\title{
Long-term effects of supplementary feeding of moose on browsing impact at a landscape scale
}

\author{
Karen Marie Mathisen ${ }^{\mathrm{a}, *}$, Jos M. Milner ${ }^{\mathrm{a}}$, Floris M. van Beest ${ }^{\mathrm{a}, \mathrm{b}}$, Christina Skarpe ${ }^{\mathrm{a}}$

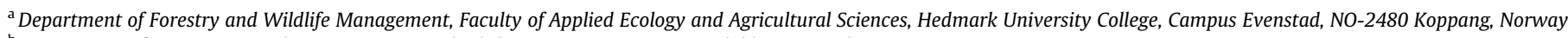 \\ ${ }^{\mathrm{b}}$ Department of Bioscience, Aarhus University, Frederiksborgvej 399, DK-4000 Roskilde, Denmark
}

\section{A R T I C L E I N F O}

\section{Article history:}

Received 11 September 2013

Received in revised form 25 November 2013

Accepted 29 November 2013

\section{Keywords:}

Alces alces

Browsing impact

Central-place foraging

Pinus sylvestris

Supplemental feeding

Diversionary feeding

\begin{abstract}
A B S T R A C T
Supplementary, or diversionary feeding of wildlife is a common management practice, increasingly used to reduce or divert herbivore impact from sensitive habitats, forestry or agriculture. The landscape-scale spatial distribution of herbivory in relation to diversionary feeding is relevant to wildlife and land management, yet has never been quantified. We considered multiple hypotheses, based on central-place foraging theory, to investigate how landscape-scale browsing impact changed as a function of distance from feeding stations and thereby test the effectiveness of diversionary feeding. We assessed the landscapescale browsing impact of moose by quantifying browsing patterns and moose density in commerciallyvaluable young Scots pine stands in an area of South-East Norway with a long history of winter feeding. We also used positions from GPS-collared female moose to investigate the spatial distribution of individuals across the landscape. Moose density and browsing impact at the local spatial scale $(<1 \mathrm{~km})$ followed an exponential decrease with distance from diversionary feeding stations. However, at the landscape scale (1-10 km), browsing impact did not show any relationship with distance to feeding stations. Leader stem browsing on Scots pine trees was high at both the local $(68 \pm 12 \%)$ and landscape $(59 \pm 8 \%)$ scales. In addition, browsing on commercially valuable Norway spruce, which is normally avoided by moose, was locally high around feeding stations. Long-term diversionary feeding of moose is ineffective in diverting browsing impact from young pine stands at the landscape scale, as currently practiced. Browsing on commercially-important tree species was sufficiently high that economic consequences could be expected. To avoid further conflict, we suggest a combination of reducing moose density and increasing the availability of natural or higher quality supplementary forage.
\end{abstract}

(C) 2013 Elsevier B.V. All rights reserved.

\section{Introduction}

Supplementary feeding of wild large herbivores is often implemented as a management tool to increase wildlife productivity (Putman and Staines, 2004; Brown and Cooper, 2006) or carrying capacity (Smith, 2001), or to mitigate human-wildlife conflicts (Andreassen et al., 2005; Barrio et al., 2010; Kowalczyk et al., 2011). In terms of mitigation, the provision of supplementary feed may change animals' habitat use, diverting them away from sensitive habitats or attracting them to sacrifice areas or refuges (i.e. diversionary feeding). Alternatively, it may increase the overall availability of forage and so reduce consumption of sensitive natural vegetation, commercial forest or agricultural crops (Peek et al., 2002; Putman and Staines, 2004; Brown and Cooper, 2006). Diversionary feeding has been used to reduce grazing in agricultural

\footnotetext{
* Corresponding author. Tel.: +47 62430 893; fax: +47 62430851.

E-mail addresses: karen.mathisen@hihm.no (K.M. Mathisen), jos.milner@gmail. com (J.M. Milner), flbe@dmu.dk (F.M. van Beest), christina.skarpe@hihm.no (C. Skarpe).
}

fields by free ranging European bison (Bison bonasus) (Kowalczyk et al., 2011), to mitigate against traffic accidents and browsing on commercially valuable young forest by moose (Alces alces) in Scandinavia (Gundersen et al., 2004; Andreassen et al., 2005; van Beest et al., 2010a), and to reduce browsing in vineyards by rabbits (Oryctolagus cuniculus) (Barrio et al., 2010). However, many studies have shown that supplementary-fed animals continue to feed on natural vegetation in the proximity of feeding stations (Doenier et al., 1997; Smith, 2001; Gundersen et al., 2004; Cooper et al., 2006). Most of these studies have been carried out at small spatial scales, whereas management of forest and wildlife often takes place at a landscape scale.

Supplementary feeding stations can be seen as spatially concentrated key resources within an animal's home range, comparable to mineral licks, salt pools or water holes (Bailey et al., 1996; Laurian et al., 2008). Such point sources of essential resources in the landscape may create radial patterns of habitat use such as the disturbance zones (piospheres) around water sources in dry rangelands (Graetz and Ludwig, 1976; Andrew, 1988; Jeltsch et al., 1997). Central-place foraging theory, an application of the wider optimal 
foraging theory, describes space-use and foraging patterns by animals that frequently return to a focal place such as a den or a nest (Orians and Pearson, 1979). It has also been used as an effective tool to describe radial patterns of habitat use in a wide range of herbivores (Gallant et al., 2004; Bakker et al., 2005; Raffel et al., 2009; Shrader et al., 2012). Central-place foraging theory predicts a decline in space use and an increase in selectivity with increasing distance from the central place (Orians and Pearson, 1979; Rosenberg and McKelvey, 1999). Although feeding stations differ from dens or water points in offering concentrated food resources, it has been shown that fine-scale movements and browsing around feeding stations create space-use patterns and foraging decisions in accordance with the predictions of central-place foraging theory (van Beest et al., 2010a,b).

Numbers of large herbivores have increased across Europe and North America during recent decades (McShea et al., 1997; Côté et al., 2004), exacerbating human-wildlife conflicts (Austin et al., 2010; Kuijper, 2011; Putman et al., 2011). In Fennoscandia, moose numbers increased dramatically between 1950 and 1980, and have since stabilized at relatively high densities, often in the order of one moose per $\mathrm{km}^{2}$ (Lavsund et al., 2003). As Scots pine (Pinus sylvestris) is an important winter forage for moose, but also an economically valuable timber species, moose browsing can lead to conflicts with commercial forestry (Hornberg, 2001). In Norway, diversionary feeding is practised in areas with high moose density to reduce browsing in young Scots pine stands. However, supplementary fed moose continue to browse on natural vegetation (Gundersen et al., 2004), and to select for young Scots pine stands (van Beest et al., 2010b). At feeding stations, browsing impact can be locally high, questioning the efficacy of diversionary feeding in reducing browsing in young Scots pine stands (van Beest et al., 2010a). The effectiveness of diversionary feeding depends on the ability of feeding stations to attract animals and so reduce browsing further away. The length and shape of the resource use gradient from a central-place, like a feeding station, varies with the resource utilised, animal species and population size, and the period of use (Jeltsch et al., 1997). This has not been quantified before in the context of supplementary feeding. If browsing impact in relation to distance from feeding stations can be predicted by central place foraging theory, it would be useful for evaluating the efficacy and placement of diversionary feeding stations.

In this study we quantified the landscape-scale spatial pattern of moose distribution and browsing up to $10 \mathrm{~km}$ from feeding stations, focusing on the diversionary aspect of supplementary feeding. This enabled us to characterise the spatial pattern of resource use as a function of distance from feeding stations, using hypotheses based on central-place foraging theory, and thereby assess whether diversionary feeding was an effective tool to reduce moose browsing on commercially valuable forests at the landscape scale. We tested three alternative hypotheses for the shape of the decline in resource use with increasing distance from the central place (feeding station) and compared them with a null-hypothesis.

$\mathbf{H}_{\mathbf{0}}$. Browsing intensity is unaffected by distance from feeding stations.

$\mathbf{H}_{\mathbf{1}}$. Browsing intensity decreases linearly with increasing distance from feeding stations (linear model; Rosenberg and McKelvey (1999)).

$\mathbf{H}_{2}$. Browsing intensity is high up to a threshold distance from feeding stations, and then drops to a lower level following the sigmoid response curve (sigmoid model) described for piospheres (Andrew, 1988; Thrash, 2000).

$\mathbf{H}_{3}$. Browsing intensity decreases rapidly with increasing distance from feeding stations (exponential decrease model) until a low background level is reached at the landscape-scale (Thrash and Derry, 1999; Nemeth et al., 2005).

If browsing impact can be predicted by Hypotheses $1-3$, they may be used to recommend the positioning of diversionary feeding stations in relation to distance from young forest stands. If browsing impact is too high to sustain timber production within a certain distance to feeding stations, this may be considered a sacrifice area.

\section{Material and methods}

\subsection{Study area}

The study was carried out in Stor-Elvdal, Åmot and Rendalen municipalities in South-East Norway $\left(\sim 61^{\circ} \mathrm{N}, 11^{\circ} \mathrm{E}\right)$, situated between 250 and 1100 m.a.s.l. The vegetation was primarily boreal forest (Moen et al., 1999) below the commercial timberline at $700 \mathrm{~m}$. It consisted of managed stands of pure or mixed Scots pine, Norway spruce (Picea abies), downy birch (Betula pubescens) and silver birch (Betula pendula), interspersed with grey alder (Alnus incana), rowan (Sorbus aucuparia), aspen (Populus tremula) and willows (Salix spp.). The field layer vegetation was dominated by dwarf shrubs such as Vaccinium spp. Weather data from the valley bottom showed 30 year mean summer (May-September) and winter (October-April) temperatures of $10.6{ }^{\circ} \mathrm{C}$ and $-5.8^{\circ} \mathrm{C}$, respectively. The 30 year mean annual precipitation was $628 \mathrm{~mm}$ and the mean snow depth (October-April) was $39 \mathrm{~cm}$ (NMI, 2008).

Moose were the dominant large herbivore in the area, with a winter population density ranging between 1.1 and 3.4 moose per $\mathrm{km}^{2}$ (Gundersen et al., 2004; Storaas et al., 2005; Milner et al., 2012a). Moose hunting is an important driver of the regional economy (Storaas et al., 2001). Simultaneously, the area is one of the most important regions for Scots pine forestry in Norway. There is therefore a conflict of interest between moose hunters and foresters. In the winter, the moose population concentrates in the lower valleys, leading to browsing damage to young pine stands. Landowners have been feeding moose with grass silage during winter since 1990, initially to divert moose away from the main road and railway but currently an estimated $60 \%$ of the moose population's winter food comes from supplementary feeding (Gundersen et al., 2004; van Beest et al., 2010a; Milner et al., 2012a). Supplementary feed is provided ad libitum for moose at fixed sites throughout the winter period (November-March). The amount supplied has increased from a few hundred $\mathrm{kg}$ in 1990 to around 200 tons in 1998 and almost 2000 tons in 2010. Simultaneously the number of feeding stations has increased to $>100$ in Stor-Elvdal alone, and the radius of the area with heavy browsing impact around feeding stations has expanded from $0.2 \mathrm{~km}$ in 1998 to $1 \mathrm{~km}$ in 2008 due to local browse depletion (van Beest et al., 2010a). During the same period, the moose density has remained relatively constant, while the number of moose shot per year was 550 in 1994-2005, and approximately 700 in 20062010 (Milner et al., 2012a).

\subsection{Field procedures}

We plotted $1 \mathrm{~km}$ interval zones around all feeding stations currently in use within the study area and surroundings ( $n=108)$, up to a distance of $10 \mathrm{~km}$, by creating buffers using ArcGIS software (ESRI 2012). The zones were overlaid on satellite maps of forest stands from the Norwegian Forest and Landscape Institute (Gjertsen, 2007), allowing us to identify young stands of pure and mixed Scots pine. We intended to sample a similar number of forest stands from each zone over $1 \mathrm{~km}$ from feeding stations but as $95 \%$ of the forested area was within $7 \mathrm{~km}$ of an active feeding station, fewer stands were sampled at distances $\geqslant 7 \mathrm{~km}$ 
(Table 1). All stands were visited to confirm that they were dominated by Scots pine and had trees of the desired height $(0.5-8 \mathrm{~m})$, with live branches within moose browsing range $\leqslant 3 \mathrm{~m}$ (Danell et al., 1985). The resulting sample consisted of 69 stands. The zone 0-1 km from feeding stations had been investigated in an earlier local-scale study (van Beest et al., 2010a), while the main focus of the current study was to evaluate landscape-scale effects. However, from a management perspective, we considered it more appropriate to evaluate both scales together, so we also included all young Scots pine stands from the previous survey. This twoscale approach was chosen because previous studies show that moose browsing pressure changes more rapidly with distance at a finer scale close to feeding stations, hence a higher sampling resolution was necessary close to feeding stations (Gundersen et al., 2004). The split between local and landscape scales was based on observation of moose browsing from more recent studies (Mathisen and Skarpe, 2011; Mathisen et al., 2012).

Forest stands were surveyed for browsing, tree density and density of moose faecal pellet groups (a proxy for moose density) using similar methods in June-July 2008 (0-1 km) and 2010 (1-10 km). However, the sampling layout differed between the two studies. At the local scale $(0-1 \mathrm{~km})$, two transects were established radiating out from each feeding station in randomly chosen directions, a minimum of $25^{\circ}$ apart. Circular plots of $50 \mathrm{~m}^{2}$ were surveyed along the transects at $12.5,25,50,100,200,500$ and $1000 \mathrm{~m}$ from feeding stations. A subset of 152 plots from 52 feeding stations were located in young Scots pine forest and these were used in the present study. At the landscape scale $(1-10 \mathrm{~km})$, four circular plots of 50 $\mathrm{m}^{2}$ were surveyed within each stand. The plots were placed $20 \mathrm{~m}$ from the centre point of each stand, in each cardinal direction $(\mathrm{N}$, $\mathrm{S}, \mathrm{E}$, and $\mathrm{W}$ ). In all plots at both scales, moose pellet groups from the previous winter were counted (Månsson et al., 2007a). Within each plot at the landscape scale, all trees taller than $0.5 \mathrm{~m}$ were counted and measured, but in the local scale study, one tree with an average height and canopy diameter per plot was measured.

For each measured tree, browsing by moose on the current leading shoot and evidence of older leader stem browsing (browsed stump visible and changed regrowth of the leading shoot) up to 3 years previously was recorded, and hereafter called leader stem browsing (browsed/non-browsed). The total number of moose browsed and unbrowsed twigs ( $>1 \mathrm{~cm}$ long) from the last growing season, occurring within a $0.5-3 \mathrm{~m}$ height range, were recorded. Browsing pressure was calculated per tree as\% browsed twigs of total number of twigs available. We also recorded whether the leader stem was broken, and if there was visible bark browsing on the stem by moose. Diameters of three bites (if present) were measured on each tree and the average was used for further analysis, as an indication of moose selection and food availability. An accumulated browsing score (Skarpe et al., 2007) was given to

\section{Table 1}

Area of forest occurring within $1 \mathrm{~km}$ distance intervals of supplementary feeding stations currently in use within the Stor-Elvdal study area, together with the number of young pine stands sampled.

\begin{tabular}{lllcc}
\hline $\begin{array}{l}\text { Buffer } \\
\text { distance }(\mathrm{km})\end{array}$ & $\begin{array}{l}\text { Area of forest } \\
\left(\mathrm{km}^{2}\right)\end{array}$ & $\begin{array}{l}\text { Forest } \\
\text { area }(\%)\end{array}$ & $\begin{array}{l}\text { Cumulative } \\
(\%)\end{array}$ & $\begin{array}{l}\text { No. stands } \\
\text { sampled }\end{array}$ \\
\hline $0-1$ & 148 & 16 & 16 & 1 \\
$1-2$ & 201 & 22 & 38 & 8 \\
$2-3$ & 175 & 19 & 58 & 7 \\
$3-4$ & 133 & 15 & 72 & 10 \\
$4-5$ & 95 & 10 & 83 & 8 \\
$5-6$ & 64 & 7 & 90 & 14 \\
$6-7$ & 45 & 5 & 95 & 14 \\
$7-8$ & 27 & 3 & 98 & 5 \\
$8-9$ & 12 & 1 & 99 & 1 \\
$9-10$ & 9 & 1 & 100 & 1 \\
\hline
\end{tabular}

each tree, to estimate cumulative effect of previous years' browsing (i.e. excluding the most recent winter). The scores were as follows: $0=$ no previous browsing, $1=$ previous browsing visible but the growth form of the tree was unchanged, 2 = previous browsing had visibly changed the growth form of the tree (such as crooked stem, increased branching), 3 = previous browsing had strongly changed the growth form of the tree (i.e. multiple leader stems, bushy form). A tree was considered damaged for forestry purposes if it fell in any of the following categories: $(1) \geqslant 60 \%$ of twigs were browsed (Solbraa, 2002), (2) an accumulated browsing score of 2 or 3, (3) stem breakage, (4) bark browsing or (5) leader stem browsing.

\subsection{Moose distribution and movements}

Twenty adult female moose were captured in the study area in January 2010 as part of a wider project (Milner et al., 2012b). Each was fitted with a GPS collar (Tellus Remote GSM, Followit AB, Lindesberg, Sweden) programmed with a 1 -hour relocation schedule (van Beest et al., 2010c; van Beest et al., 2011). Due to the longterm and extensive nature of the feeding programme, all but 5 individuals spent at least $10 \%$ of their time between January and end of March within $100 \mathrm{~m}$ of feeding stations. As the spatial behaviour of these 5 individuals was not related to feeding stations, we considered them separately (non-users, $n=5$ ) from the other individuals (feeding station users, $n=15$ ). Feeding station users spent $71.7 \%$ of their time within $1 \mathrm{~km}$ of feeding stations and a median of $3.8 \mathrm{~h}$ per day (range 2.5-9.5 h) within $100 \mathrm{~m}$ of feeding stations, whereas non-users spent only $6.6 \%$ of their time within $1 \mathrm{~km}$.

\subsection{Statistics}

The effect of distance from feeding stations on browsing impact was analysed for the three most common tree species; Scots pine, Norway spruce and downy birch. Of these, pine and birch are of intermediate preference whilst spruce is generally less preferred by moose (Månsson et al., 2007b). Other more preferred forage species, such as rowan, aspen and willow (Månsson et al., 2007b), had very low abundance, and hence did not occur at an adequate sample size to evaluate the effect of distance from feeding stations on browsing impact (Table 3). Pine and spruce are both commercially important species, and pine and downy birch are important winter browse for moose. To explore possible nonlinear effects of distance from feeding stations (Hypotheses 2 and 3), we used generalised additive mixed models (GAMM; (Wood, 2006)) from the library 'mgcv' in the program R 2.15 (R Development Core Team, 2012). Moose pellet group counts were analysed with a Poisson error distribution and a log-link function, whereas proportions of shoots browsed and leader stem browsing were analysed with a binomial error distribution and a logit link function. To account for dependency of measurements from the same locality (side-valley), locality/stand ID/plot ID (landscape scale) or feeding station ID (local scale) were fitted as nested random intercepts where appropriate. Distance from the nearest active feeding station was fitted as a smoothing term. We used thin plate regression splines, with the optimal smooth curve estimated by the generalised cross-validation procedure (Wood, 2006). The output from a GAMM gives the effective degrees of freedom for a smoother, where a value $>1$ indicates non-linearity (Zuur et al., 2009). This method allowed us to explore the shape of the function describing moose use in relation to distance from feeding stations, and we could use the amount of smoothing to separate the linear hypothesis (H1) from the non-linear hypotheses ( $\mathrm{H} 2$ and $\mathrm{H} 3$ ). We used $p<0.001$ to indicate significance, according to Zuur et al. (2009). As preliminary GAMMs showed that most significant effects showed exponential decreases 
Table 2

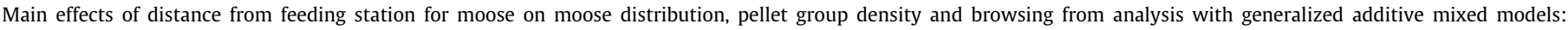
approximate $p$-values for the effect of the smoothing term distance from the closest active feeding station and estimated degrees of freedom (edf).

\begin{tabular}{|c|c|c|c|c|c|}
\hline & Response & Edf & F-Value & $p$-Value & $R^{2}$ \\
\hline \multicolumn{6}{|l|}{ Feeding station use } \\
\hline Feeding station users & Proportion of time & 8.31 & 31.27 & $<0.001$ & 0.935 \\
\hline Non-users & & 4.92 & 2.692 & 0.059 & 0.445 \\
\hline \multicolumn{6}{|l|}{ Local scale $\leqslant 1 \mathrm{~km}$} \\
\hline Moose & Pellet groups & 3.66 & 1774 & $<0.001$ & 0.156 \\
\hline \multirow{2}{*}{ Scots pine } & Leader stem browsing & 1 & 0.004 & 0.951 & 0.018 \\
\hline & Browsing pressure & 3.98 & 148.5 & $<0.001$ & 0.792 \\
\hline \multirow[t]{2}{*}{ Norway spruce } & Leader stem browsing & 1 & 2.978 & 0.084 & 0.033 \\
\hline & Browsing pressure & 3.9 & 424.4 & $<0.001$ & 0.282 \\
\hline Downy birch & Browsing pressure & 2.61 & 45.38 & $<0.001$ & 0.114 \\
\hline \multicolumn{6}{|l|}{ Landscape scale $1-10 \mathrm{~km}$} \\
\hline Moose & Pellet groups & 1 & 1.57 & 0.210 & 0.012 \\
\hline \multirow[t]{2}{*}{ Scots pine } & Leader stem browsing & 1 & 0.277 & 0.599 & 0.015 \\
\hline & Browsing pressure & 1 & 0.746 & 0.388 & 0.113 \\
\hline \multirow[t]{2}{*}{ Norway spruce } & Leader stem browsing & 1 & 8.42 & 0.004 & 0.025 \\
\hline & Browsing pressure & 1 & 7.69 & 0.006 & 0.007 \\
\hline Downy birch & Browsing pressure & 1 & 0.73 & 0.394 & 0.320 \\
\hline
\end{tabular}

with distance from feeding stations, an exponential decrease model (H3) was fitted using non-linear least-squares regression. Analyses were carried out separately for the local scale and the landscape scale because the difference in sample sizes gave rise to spurious non-linear effects at $1 \mathrm{~km}$ from feeding stations, where the scales changed. We assessed whether browsing impact differed between the two scales using $t$-tests assuming unequal variances to compare tree densities, whereas linear and generalized linear models were used to compare browsing intensity between the two scales. All mean values are presented with \pm 2 SE.

The proportion of moose GPS locations occurring within $500 \mathrm{~m}$ intervals from feeding stations were determined separately for feeding station users and non-users and scaled by the availability of forest habitat within each interval (Table 1) to relate time use to the available area. The frequency distribution of locations was analysed using the procedure described above for pellet group counts.

\section{Results}

\subsection{Moose spatial distribution in a landscape with feeding stations}

Moose pellet group density showed a significant exponential decrease (sensu H3; $y=58.48 \mathrm{e}^{-18.22 x}$ ) with distance $(\mathrm{m})$ from feeding stations at the local scale $(0-1 \mathrm{~km})$, but no significant pattern (sensu $\mathrm{H} 0$ ) at the landscape scale (1-10 km; Table 2, Fig. 1a). The GPS collared moose that used feeding stations also showed an exponential decrease $\left(y=408.7 \mathrm{e}^{-2.36 x}\right)$ in time spent $(\mathrm{h})$ at locations with increasing distance from feeding stations, while the distribution of those individuals not using feeding stations appeared bimodal (Table 2; Fig. 1b). The bimodal distribution was an artefact of the low sample size of non-feeders, clustered in 3 locations at 2 different distances from feeding stations rather than having any biological significance. Feeding station users made more long daily movements than non-users, on average $45 \pm 6.8$ movements $>500 \mathrm{~m}$ per individual during the winter season, compared with $15 \pm 7.0$ by non-users $\left(F_{1,18}=23.5 ; p<0.001\right)$. Mean daily distance moved by users was $1862 \pm 127.2 \mathrm{~m}$, which was approximately twice the distance moved by non-users $(980 \pm 226 \mathrm{~m}$; $\left.F_{1,18}=47.57 ; p<0.001\right)$. The moose using feeding stations visited a total of 39 different feeding stations, ranging from 1 to 9 feeding stations per moose.

\subsection{Moose browsing at the landscape scale}

\subsubsection{Tree species composition}

On average, only $30 \%$ of all Scots pine trees per stand were undamaged by moose browsing, and the density of undamaged Scots pine was low compared to that of Norway spruce at a landscape scale (Table 3 ). At the local scale, $\leqslant 1 \mathrm{~km}$ from feeding stations, Scots pine density (damaged and undamaged trees) was $68 \%$ lower than at the landscape scale $(t=5.41, d F=93, p<0.001$, Table 3), and Norway spruce and downy birch were the most common species (Table 3).

\subsubsection{Scots pine}

The proportion of Scots pine leader stems browsed did not change significantly with distance from feeding stations at either spatial scale (sensu H0; Table 2, Fig. 2b) or differ between scales (local: $68 \pm 12 \%$, landscape: $59 \pm 8 \%, \chi^{2}=1.16, p=0.282$, Table 3 ). At the local scale browsing pressure on Scots pine showed a humped relationship peaking at $500 \mathrm{~m}$, but at the landscape scale it did not show any relationship with distance from feeding stations (sensu H 0; Table 2, Fig. 2a). Average browsing pressure on Scots pine was lower at the local $(18 \pm 9 \%)$ than at the landscape scale $\left(33 \pm 7 \%, F_{1,119}=7.37, p=0.008\right)$. There was a large variation in both leader stem browsing ( $S D=31 \%$, range $0-100 \%$ ) and browsing pressure ( $S D=27 \%$, range $0-100 \%$ ) between stands at the landscape scale. The average bite diameter was larger at the local scale (local: $\quad 4.6 \pm 0.7 \mathrm{~mm}$, landscape: $\quad 3.9 \pm 0.2 \mathrm{~mm} \quad F_{1,72}=8.42$, $p=0.005)$, reflecting the lower local availability of pine. Accumulated browsing on pine showed no significant difference between local and landscape scale (local: $1.59 \pm 0.25$, landscape: $\left.1.35 \pm 0.19, F_{1,142}=2.24, p=0.137\right)$. Only $1.8 \pm 1.8 \%$ of the pines showed signs of bark browsing at the landscape scale and $1.7 \pm 2.5 \%$ at the local scale. Stem breakage of pine was also low (local scale $2.1 \pm 2.7 \%$, landscape scale: $0.6 \pm 0.6 \%$ ).

\subsubsection{Norway spruce}

Leader stem browsing on Norway spruce did not change significantly with distance from feeding stations at the local scale (Table 2, Fig. 2d), while at the landscape scale, it showed a tendency to increase with increasing distance (Table 2, Fig. 2d). However, the effect was marginal and probably caused by large variation and a small sample size at distances $>8 \mathrm{~km}$ from feeding stations. Leader stem browsing was higher at the local than at the landscape scale (local: $30 \pm 10 \%$, landscape: $6 \pm 4 \%, \chi^{2}=13.46, p<0.001$ ). 
Table 3

Browsing pressure and browse availability (means $\pm 2 \mathrm{SE}$ ) across tree species sampled at local (0-1 km from moose feeding stations (FS)) and landscape (1-10 km) scales.

\begin{tabular}{|c|c|c|c|c|c|c|c|c|}
\hline Species & ${ }^{\mathrm{a}}$ Plots /FS 0-1 km & $\begin{array}{l}\text { Leader stem } \\
\text { browsing (\%) }\end{array}$ & $\begin{array}{l}\text { Browsing } \\
\text { pressure (\%) }\end{array}$ & $\begin{array}{l}\text { Accumulated } \\
\text { browsing }(0-3)\end{array}$ & $\begin{array}{l}\text { Bite diameter } \\
(\mathrm{mm})\end{array}$ & $\begin{array}{l}\text { Available twigs } \\
\text { per tree }\end{array}$ & $\begin{array}{l}\text { Tree density } \\
\text { (trees ha }^{-1} \text { ) }\end{array}$ & $\begin{array}{l}{ }^{\mathrm{b}} \text { Distance } \\
\text { from FS (m) }\end{array}$ \\
\hline \multicolumn{9}{|c|}{ Local scale 0-1 km from FS } \\
\hline Scots pine & $81 / 44$ & $68 \pm 12$ & $17.7 \pm 9.1$ & $1.59 \pm 0.25$ & $4.59 \pm 0.69$ & $23 \pm 25$ & $737 \pm 234$ & 244 \\
\hline Norway spruce & $139 / 42$ & $30 \pm 10$ & $6.6 \pm 3.2$ & $0.88 \pm 0.16$ & $3.35 \pm 0.47$ & $276 \pm 92$ & $1492 \pm 420$ & 216 \\
\hline Downy birch & $129 / 43$ & $69 \pm 9$ & $19.4 \pm 5.4$ & $1.53 \pm 0.16$ & $2.71 \pm 0.25$ & $25 \pm 6$ & $1308 \pm 301$ & 189 \\
\hline Silver birch & $28 / 12$ & $63 \pm 20$ & $33.7 \pm 14.5$ & $1.85 \pm 0.36$ & $2.74 \pm 0.27$ & $26 \pm 11$ & $495 \pm 370$ & 81 \\
\hline Rowan & $29 / 15$ & $73 \pm 18$ & $37.6 \pm 19.5$ & $1.93 \pm 0.34$ & $2.44 \pm 0.98$ & $3 \pm 2$ & $117 \pm 111$ & 154 \\
\hline Salix & $43 / 21$ & $77 \pm 14$ & $25.1 \pm 11.8$ & $1.67 \pm 0.34$ & $2.55 \pm 0.62$ & $33 \pm 29$ & $426 \pm 232$ & 122 \\
\hline Aspen & $10 / 7$ & $57 \pm 40$ & $4.2 \pm 8.3$ & $0.78 \pm 0.73$ & $3.00 \pm 0.00$ & $7 \pm 6$ & $116 \pm 134$ & 86 \\
\hline Juniper & $1 / 1$ & $100 \pm$ n.a. & n.a. & $2.00 \pm$ n.a. & n.a. & $0 \pm$ n.a. & $4 \pm 8$ & 200 \\
\hline Alder & $8 / 5$ & $60 \pm 49$ & $28.5 \pm 28.7$ & $1.38 \pm 0.53$ & $3.26 \pm 0.41$ & $18 \pm 14$ & $529 \pm 537$ & 16 \\
\hline Species & $\begin{array}{l}{ }^{\mathrm{c}} \mathrm{Stands} \\
1-10 \mathrm{~km}\end{array}$ & $\begin{array}{l}\text { Leader stem } \\
\text { browsing (\%) }\end{array}$ & $\begin{array}{l}\text { Browsing } \\
\text { pressure (\%) }\end{array}$ & $\begin{array}{l}\text { Accumulated } \\
\text { browsing (0-3) }\end{array}$ & $\begin{array}{l}\text { Bite diameter } \\
(\mathrm{mm})\end{array}$ & $\begin{array}{l}\text { Available twigs } \\
\text { per tree }\end{array}$ & 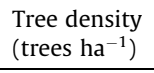 & $\begin{array}{l}\text { Trees undamaged } \\
\text { by moose }\left(\text { ha }^{-1}\right)\end{array}$ \\
\hline \multicolumn{9}{|c|}{ Landscape scale $1-10 \mathrm{~km}$ from $\mathrm{FS}$} \\
\hline Scots pine & 63 & $59 \pm 8$ & $33 \pm 7$ & $1.35 \pm 0.19$ & $3.87 \pm 0.17$ & $51 \pm 18$ & $2275 \pm 518$ & $696 \pm 195$ \\
\hline Norway spruce & 58 & $6 \pm 4$ & $0.5 \pm 0.4$ & $0.08 \pm 0.04$ & $3.34 \pm 0.34$ & $1031 \pm 519$ & $1130 \pm 424$ & $1051 \pm 401$ \\
\hline Downy birch & 52 & $66 \pm 9$ & $27 \pm 6$ & $1.57 \pm 0.21$ & $1.98 \pm 0.12$ & $77 \pm 30$ & $1503 \pm 688$ & $576 \pm 322$ \\
\hline Silver birch & 34 & $77 \pm 11$ & $34 \pm 9$ & $1.68 \pm 0.28$ & $2.34 \pm 0.26$ & $56 \pm 31$ & $681 \pm 402$ & $153 \pm 113$ \\
\hline Rowan & 29 & $88 \pm 8$ & $44 \pm 9$ & $1.96 \pm 0.24$ & $2.53 \pm 0.33$ & $7 \pm 2$ & $366 \pm 228$ & $18 \pm 14$ \\
\hline Salix & 24 & $74 \pm 14$ & $42 \pm 12$ & $1.85 \pm 0.43$ & $2.53 \pm 0.38$ & $46 \pm 40$ & $213 \pm 106$ & $42 \pm 34$ \\
\hline Aspen & 10 & $86 \pm 20$ & $44 \pm 20$ & $2.13 \pm 0.54$ & $2.69 \pm 0.35$ & $8 \pm 4$ & $213 \pm 248$ & $12 \pm 14$ \\
\hline Juniper & 10 & $63 \pm 26$ & $11 \pm 12$ & $1.41 \pm 0.65$ & $2.40 \pm 0.63$ & $196 \pm 90$ & $79 \pm 55$ & $29 \pm 26$ \\
\hline Alder & 4 & $50 \pm 45$ & $35 \pm 45$ & $0.90 \pm 0.83$ & $2.85 \pm 0.61$ & $44 \pm 76$ & $90 \pm 106$ & $58 \pm 68$ \\
\hline
\end{tabular}

a "Plots" gives the number of plots and corresponding number of feeding stations that each species was present at, from a total of 468 plots and 44 feeding stations surveyed along transects radiating out from feeding stations at the local scale.

b "Distance from FS" gives the mean distance from feeding stations for the plots where the species was present.

c "Stands" gives the number of stands where each species was present from a total of 69 young forest stands surveyed at the landscape scale.
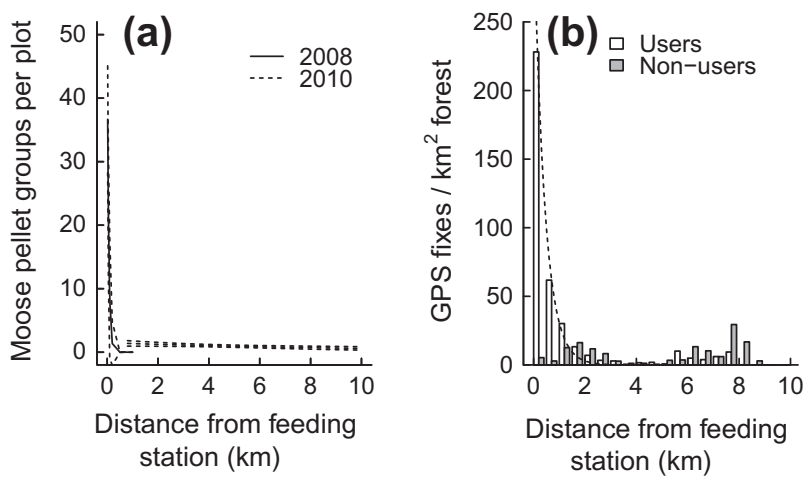

Fig. 1. (a) Moose winter pellet groups (per $50 \mathrm{~m}^{2}$ ) in relation to distance from feeding stations. An exponential curve was fitted at the local scale $(0-1 \mathrm{~km}$ from feeding stations, data from 2008) and a line from the GAMM with 95\% CIs at the landscape scale (1-10 km, data from 2010). (b) Proportion of time spent by GPSmarked moose (GPS fixes ( 1 per hr) per $\mathrm{km}^{2}$ forest area) in relation to distance from feeding stations in the winter of 2010 , for feeding station users $(n=15)$ and nonusers $(n=5)$. An exponential decrease model (dotted line) was fitted to the feeding station user data.

Browsing pressure showed an exponential decrease with increasing distance (sensu $\mathrm{H} 3 ; y=0.10 \mathrm{e}^{-0.003 x}$ ) at the local scale, but no significant effect at the landscape scale (sensu HO; Table 2, Fig. 2c) and was higher at the local than at the landscape scale (local: $6.6 \pm 3.2 \%$, landscape: $0.5 \pm 0.4 \%, F_{1,183}=6.39, p=0.012$ ). Accumulated browsing on spruce was also higher at the local than the landscape scale (local: $0.88 \pm 0.16 \%$, landscape: $0.08 \pm 0.04 \%$, $\left.F_{1,193}=42.42, p<0.001\right)$.

\subsubsection{Downy birch}

Browsing pressure on downy birch, the most common deciduous species (Table 3), showed an exponential decrease (sensu H3; $y=0.28 \mathrm{e}^{-0.003 x}$ ) with increasing distance from feeding stations at a local scale, but no significant distance effect at the landscape scale (Table 2, Fig. 2e). Browsing pressure on downy birch showed a tendency to be lower at the local than at the landscape scale (local: $19.4 \pm 5.4 \%$, landscape: $27 \pm 6 \%, F_{1,169}=2.97, p=0.087$ ). The number of twigs available per tree was also lower at the local than at the landscape scale (local: $25 \pm 6$, landscape: $77 \pm 30, F=31.33$, $p<0.001$ ), and bite diameters were larger at the local than at the landscape scale (local: $2.71 \pm 0.25 \mathrm{~mm}$, landscape: $1.98 \pm$ $\left.0.12 \mathrm{~mm}, F_{1,107}=25.85, p<0.001\right)$.

\section{Discussion}

\subsection{Browsing impact and distance to the central place}

Our results were consistent with prediction of central-place foraging theory (Rosenberg and McKelvey, 1999) but only on a local scale as moose density and browsing impact generally decreased with distance from feeding stations $(0-1 \mathrm{~km})$. In contrast, we found no effect of distance to feeding stations on species-specific browsing impact at a landscape-scale $(1-10 \mathrm{~km})$ after 20 years of diversionary feeding. Of the three proposed central-place foraging models, the exponential decrease model H3; (Thrash and Derry, 1999; Nemeth et al., 2005) best characterised moose spatial distribution and browsing on Norway spruce and downy birch at the local scale. However, for Scots pine and, to a lesser extent, downy birch, both important winter forage species, there was a resource depletion zone observed within 200 m of feeding stations (van Beest et al., 2010a), and a reduced local density of pine trees. This confirms concerns about range degradation close to feeding sites (Cooper et al., 2006) and corresponds with reports of resource depletion common around central places (Fryxell, 1992; Thrash and Derry, 1999; Elliott et al., 2009; Shrader et al., 2012). Furthermore, it suggests that diversionary feeding has been ineffective in reducing landscape-level leader stem browsing on Scots pine, a commercially valuable tree species.

An outward expansion of forage depletion around feeding stations has previously been observed (van Beest et al., 2010a), similar to the expansion of piosphere zones around water holes (Jeltsch et al., 1997; Thrash and Derry, 1999). Nonetheless, the highest 

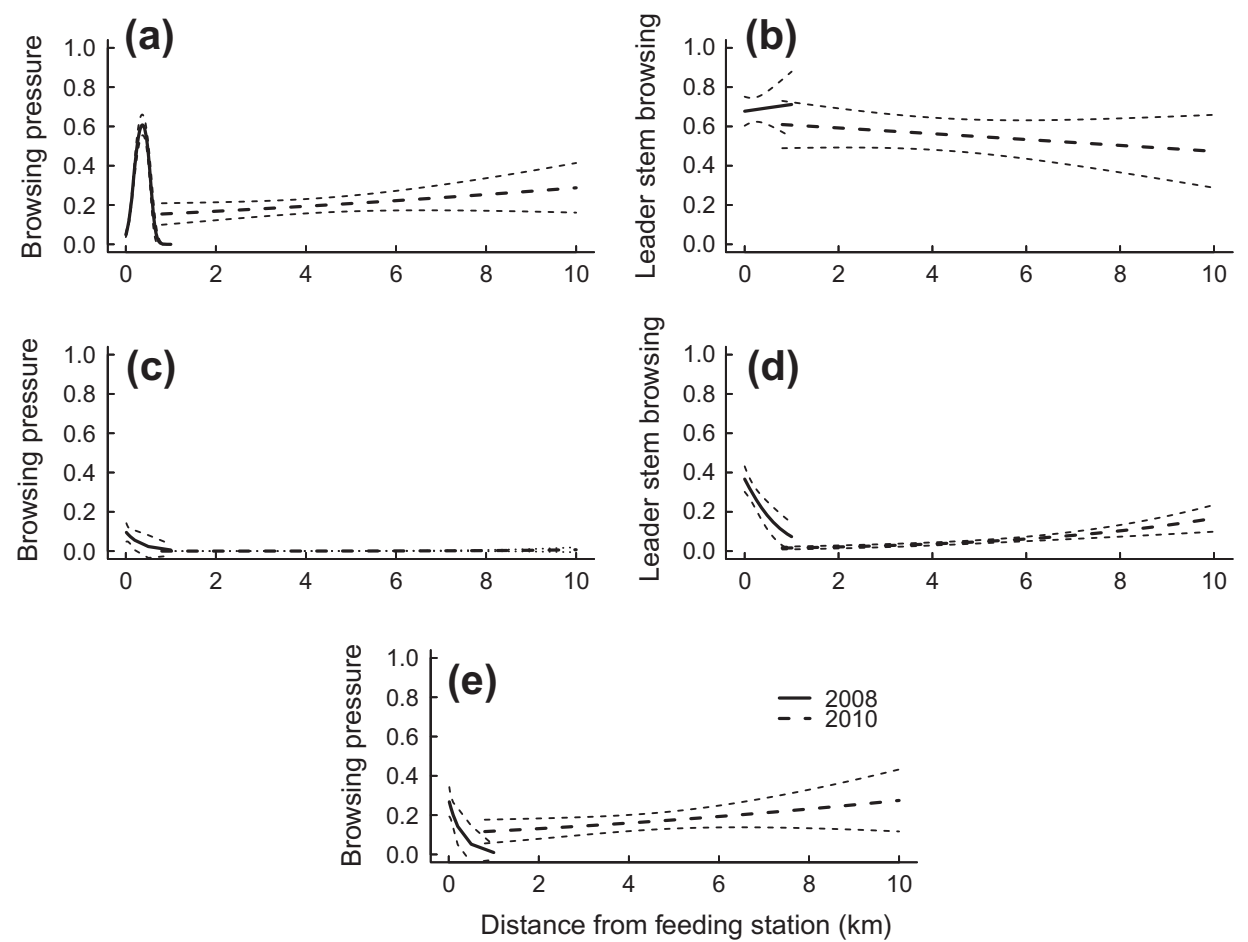

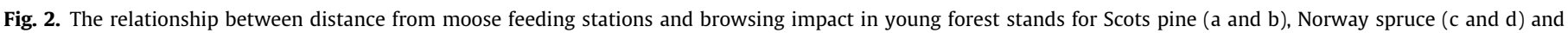

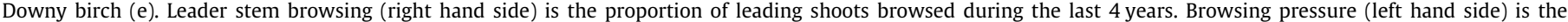

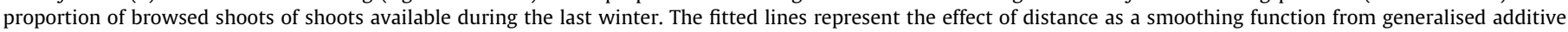

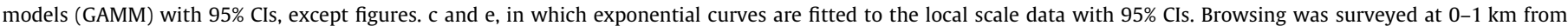
feeding stations in 2008, and at 1-10 km from feeding stations in 2010.

moose impact was restricted to the area within $1 \mathrm{~km}$ of feeding stations, likely due to constraints on daily movement. Herbivore daily travel distance is the most important factor affecting the extent of piosphere zones (Jeltsch et al., 1997; Thrash and Derry, 1999). In moose as well as other large herbivores in seasonal environments, movements in winter are restricted by snow and low food quality and availability, with reports of daily travel distances around $1 \mathrm{~km}$ (Persson et al., 2000). Deep snow is also known to restrict other deer species close to feeding grounds (Romme et al., 1995; Doenier et al., 1997; Rinella et al., 2012). In our study, feeding station users moved more than non-users, with average daily travel distances of $1.8 \mathrm{~km}$. Their effects on the vegetation would generally be restricted to an area around feeding stations with a radius of approximately half this distance, which corresponds well with the local scale where we found effects of distance to feeding stations on browsing impact.

Input of supplementary feed and moose use of feeding stations has increased over time in our study area (van Beest et al., 2010a; Milner et al., 2012a). A decrease in browsing impact with distance from feeding stations has previously been reported at landscape scales, at 5-10 years after feeding station establishment (Gundersen et al., 2004; Tange, 2007). By contrast, and in line with our null model, browsing impact on Scots pine was uniformly high across the landscape after 20 years of diversionary feeding. Nonetheless, we observed a high variability in browsing between stands, suggesting that the potential for a gradient in pine browsing with distance did exist. The steep gradient in moose use within $1 \mathrm{~km}$ of feeding stations and the lack of any gradient at a landscape scale, may be due to a higher proportion of the moose population using feeding stations than earlier (Milner et al., 2012a), indicating that the effect of feeding stations on browsing impact changes over time. Browsing in the wider landscape was primarily caused either by non-users, estimated to be around $26 \%$ of the population
(Milner et al., 2012a), or by feeding station users during periodic forays away from feeding stations or in the time period before or after migration. So even though a high proportion of the moose population used feeding stations, browsing impact at the landscape scale was still high.

\subsection{Food availability and forest damage at the landscape scale}

Leader stem browsing on Scots pine changes the architecture of the tree, causing damage from a forestry perspective (Bergqvist et al., 2001). While browsing on less preferred species such as spruce (Månsson et al., 2007b) declined with distance from the feeding stations as expected from central-place foraging theory (Orians and Pearson, 1979), the more preferred Scots pine was heavily browsed at all distances. Although Scots pine is of intermediate preference for moose, the top shoot may be preferred because of their large bite size (Shipley, 2007). If moose prefer pine tops to silage, this may explain why the current supplementary feeding practice fails to reduce browsing impact on important forage species. Seasonal resource depletion of preferred species to moose has been reported in other areas in Norway (van Beest et al., 2010c). Furthermore, a study of moose winter diet at feeding stations in our study area, showed a seasonal decrease in the proportion of pine, and an increase in spruce in the diet during winter (Nanji, 2013), suggesting depletion of available pine browse early in winter. Observations on browsing on non-preferred species and higher movement at feeding stations may indicate that grass silage is not an adequate winter food for moose. In addition, their physiology and browsing behaviour may change depending on the quality of the food provided, as observed in supplementary fed red deer (Arnold et al., 2004). To improve the efficacy of supplementary feeding, further research should investigate if the quality of 
supplementary feed can be improved, and how moose physiology responds to supplementary feeding.

The high accumulated browsing impact on Scots pine at the landscape scale indicates a long period of high moose density relative to the natural forage availability in the area. This is consistent with general changes in forestry in Fennoscandia, whereby the area of clear-felled forest, and subsequently successional forest, is declining yet hunting interests keep the moose population high (Lavsund et al., 2003; Milner et al., 2013). Consequently the availability of natural browse per head of moose is now lower than it has been for many decades (Lavsund et al., 2003; Milner et al., 2013). Browsing on non-commercial species, including non-preferred species such as alder, was also high at a landscape scale, indicating low forage availability (Edenius, 1991). Although Scots pine was the dominant tree species in the young forest stands surveyed, the density of undamaged Scots pines was low because of the high browsing impact, while the density of undamaged Norway spruce was high. Consequently the dominance is shifting from Scots pine to Norway spruce due to current forestry trends (Nilsson et al., 2012) and, possibly, to changing competitive hierarchies caused by browsing (Pastor and Naiman, 1992). This, in turn, will further reduce natural moose forage availability over time, and exacerbate conflicts between forestry and hunting interests. Therefore, to reduce the problem with high moose browsing damage in the long term, the relationship between natural forage availability and moose density must be addressed. As moose forage availability is strongly influenced by commercial forestry activities, there is a potential to increase the natural forage availability through changes in forest management (Månsson et al., 2010), which could in turn reduce browsing damage on pine.

\section{Conclusions}

In theory, supplementary feeding may reduce browsing impact in two ways: (1) by creating a spatial gradient in browsing impact (diversionary feeding) or (2) by substituting natural forage so reducing total browsing impact (supplementary feeding) or by both (1 and 2). This study demonstrates that although winter feeding in an area with a high herbivore density relative to forage availability may be successful in attracting individuals to a sacrifice area close to feeding stations, it may not have the desired diversionary effect in reducing browsing damage to valuable trees and habitats at the landscape-scale. We show that young pine stands and especially top shoots from pine remain heavily utilised by moose regardless of the presence of less preferred forage at feeding stations. At present, it would be difficult to sustain the high moose population without supplementary feeding given the current availability of natural forage in our study system. Thus, the provision of large amounts of supplementary forage has increased the carrying capacity for wintering moose (Peek et al., 2002; Putman and Staines, 2004; Brown and Cooper, 2006; Mysterud, 2010) rather than reduced forest damage by replacing natural forage. To avoid further conflict between moose hunters and forest owners, we suggest a combination of reducing the moose density and increasing the availability of natural forage as well as improving the quality of supplemental feed.

As large herbivore numbers rise across the northern hemisphere, wildlife-forestry conflicts are expected to increase (Kuijper, 2011). The application of feeding as a diversionary tool requires knowledge of preferences by the herbivore, and continuous monitoring of herbivore density, forage availability and damage to the resources to be protected (Morellet et al., 2007). Comparing this study with previous studies from the same area (Gundersen et al., 2004), also shows that the extent and effects of supplementary feeding systems may change over time, which highlights the need for long-term planning when feeding programs are initiated. In many situations a more integrated management of renewable natural resources, including large herbivores, is necessary to secure the future economic and ecological sustainability of managed ecosystems.

\section{Acknowledgements}

Financial support for this study was provided by Hedmark University College, Norwegian Research Council (173868/AREAL), Innovation Norway, and Hedmark County. We thank all the field assistants who collected browsing data and to Knut B. Nicolaysen and Tor Taraldsrud for their assistance during moose capturing. We are also grateful to Stor-Elvdal Landowners' Association and Åmot and Rendalen municipalities for information about supplementary feeding. GPS data were collected in collaboration with Fritzöe Skoger, Løvenskiold-Fossum and Stor-Elvdal Landowners' Association. All work carried out during this study conforms to the legal requirements set by 'Forsøksdyrutvalget' (Animal Research Committee) in Norway.

\section{References}

Andreassen, H.P., Gundersen, H., Storaas, T., 2005. The effect of scent-marking, forest clearing, and supplemental feeding on moose-train collisions. J. Wildl. Manage. 69, 1125-1132.

Andrew, M.H., 1988. Grazing impact in relation to livestock watering points. Trends Ecol. Evol. 3, 336-339. http://dx.doi.org/10.1016/0169-5347(88), 90090-0.

Arnold, W., Ruf, T., Reimoser, S., Tataruch, F., Onderscheka, K., Schober, F., 2004 Nocturnal hypometabolism as an overwintering strategy of red deer (Cervus elaphus). Am. J. Physiol.- Regul. Integr. Comp. Physiol. 286, R174-R181. http:// dx.doi.org/10.1152/ajpregu.00593.2002.

Austin, Z., Smart, J.C.R., Yearley, S., Irvine, R.J., White, P.C.L., 2010. Identifying conflicts and opportunities for collaboration in the management of a wildlife resource: a mixed-methods approach. Wildl. Res. 37, 647-657. http:// dx.doi.org/10.1071/wr10057.

Bailey, D.W., Gross, J.E., Laca, E.A., Rittenhouse, L.R., Coughenour, M.B., Swift, D.M., Sims, P.L., 1996. Mechanisms that result in large herbivore grazing distribution patterns. J. Range Manage. 49, 386-400. http://dx.doi.org/10.2307/4002919.

Bakker, E.S., Reiffers, R.C., Olff, H., Gleichman, J.M., 2005. Experimental manipulation of predation risk and food quality: effect on grazing behaviour in a central-place foraging herbivore. Oecologia 146, 157-167. http://dx.doi.org/10.1007/s00442005-0180-7.

Barrio, I.C., Bueno, C.G., Tortosa, F.S., 2010. Alternative food and rabbit damage in vineyards of Southern Spain. Agric. Ecosyst. Environ. 138, 51-54. http:// dx.doi.org/10.1016/j.agee.2010.03.017.

Bergqvist, G., Bergström, R., Edenius, L., 2001. Patterns of stem damage by moose (Alces alces) in young Pinus sylvestris stands in Sweden. Scand. J. Forest Res. 16, 363-370.

Brown, R.D., Cooper, S.M., 2006. The nutritional, ecological, and ethical arguments against baiting and feeding white-tailed deer. Wildl. Soc. Bull. 34, 519-524. http://dx.doi.org/10.2193/0091-7648(2006) 34[519:tneaea]2.0.co;2.

Cooper, S.M., Owens, M.K., Cooper, R.M., Ginnett, T.F., 2006. Effect of supplemental feeding on spatial distribution and browse utilization by white-tailed deer in semi-arid rangeland. J. Arid. Env. 66, 716-726. http://dx.doi.org/10.1016/ j.jaridenv.2005.11.015.

Côté, S.D., Rooney, T.P., Tremblay, J.P., Dussault, C., Waller, D.M., 2004. Ecological impacts of deer overabundance. Ann. Rev. Ecol. Evol. Syst. 35, 113-147.

Danell, K., Huss-Danell, K., Bergstrom, R., 1985. Interactions between browsing moose and 2 species of birch in Sweden. Ecology 66, 1867-1878.

Doenier, P.B., DelGiudice, G.D., Riggs, M.R., 1997. Effects of winter supplemental feeding on browse consumption by white-tailed deer. Wildl. Soc. Bull. 25, 235-243.

Edenius, L., 1991. The effect of resource depletion on the feeding-behavior of a browser - winter foraging by moose on Scots pine. J. Appl. Ecol. 28, 318-328.

Elliott, K.H., Woo, K.J., Gaston, A.J., Benvenuti, S., Dall'Antonia, L., Davoren, G.K. 2009. Central-place foraging in an arctic seabird provides evidence for StorerAschmole's halo. Auk 126, 613-625. http://dx.doi.org/10.1525/auk.2009.08245.

ESRI, 2012. ArcMap. In: ArcGIS. Environmental Systems Research Institute Inc.

Fryxell, J.M., 1992. Space use by beavers in relation to resource abundance. Oikos 64, 474-478. http://dx.doi.org/10.2307/3545163.

Gallant, D., Berube, C.H., Tremblay, E., Vasseur, L., 2004. An extensive study of the foraging ecology of beavers (Castor canadensis) in relation to habitat quality. Can. J. Zool. - Rev. Can. Zool. 82, 922-933. http://dx.doi.org/10.1139/z04-067.

Gjertsen, A.K., 2007. Accuracy of forest mapping based on Landsat TM data and kNN-based method. Remote Sens. Environ. 110, 420-430. http://dx.doi.org/ 10.1016/j.rse.2006.08.018. 
Graetz, R., Ludwig, J., 1976. A method for the analysis of piosphere data applicable to range assessment. In: Rangel, J. (Ed.), vol. 1, pp. 126-136. <http://dx.doi.org/ 10.1071/RJ9780126>.

Gundersen, H., Andreassen, H.P., Storaas, T., 2004. Supplemental feeding of migratory moose Alces alces: forest damage at two spatial scales. Wildl. Biol. $10,213-223$.

Hornberg, S., 2001. The relationship between moose (Alces alces) browsing utilisation and the occurrence of different forage species in Sweden. For. Ecol. Manage. 149, 91-102.

Jeltsch, F., Milton, S.J., Dean, R.J., van Rooyen, N., 1997. Simulated pattern formation around artificial waterholes in the semi-arid Kalahari. J. Veg. Sci. 8, 177-188.

Kowalczyk, R., Taberlet, P., Coissac, E., Valentini, A., Miquel, C., Kaminski, T., Wojcik, J.M., 2011. Influence of management practices on large herbivore diet-case of European bison in Bialowieza Primeval Forest (Poland). For. Ecol. Manage 261, 821-828. http://dx.doi.org/10.1016/j.foreco.2010.11.026.

Kuijper, D.P.J., 2011. Lack of natural control mechanisms increases wildlife-forestry conflict in managed temperate European forest systems. Eur. J. For. Res. 130, 895-909. http://dx.doi.org/10.1007/s10342-011-0523-3.

Laurian, C., Dussault, C., Ouellet, J.P., Courtois, R., Poulin, M., Breton, L., 2008 Behavioral adaptations of moose to roadside salt pools. J. Wildl. Manage. 72 1094-1100. http://dx.doi.org/10.2193/2007-504.

Lavsund, S., Nygren, T., Solberg, E.J., 2003. Status of moose populations and challenges to moose management in Fennoscandia. Alces 39, 109-130.

Mathisen, K.M., Pedersen, S., Nilsen, E.B., Skarpe, C., 2012. Contrasting responses of two passerine bird species to moose browsing. 58, 535-547. http://dx.doi.org 10.1007/s10344-011-0601-3.

Mathisen, K.M., Skarpe, C., 2011. Cascading effects of moose (Alces alces) management on birds. Ecol. Res. 26, 563-574. http://dx.doi.org/10.1007 s11284-011-0815-6.

McShea, W.J., Underwood, H.B., Rappole, J.H., 1997. The Science of Overabundance: Deer Ecology and Population Management. Smithsonian Institution Press, Washington, D.C..

Milner, J.M., Storaas, T, van Beest, F.M., Lien, G., 2012a. Sluttrapport for elgfôringsprosjektet (English abstract). Oppdragsrapport nr 1-2012. Hedmark University College, Elverum, Norway. <http://brage.bibsys.no/hhe/bitstream URN:NBN:no-bibsys_brage_26766/1/opprapp01_2012.pdf>.

Milner, J.M., van Beest, F.M., Solberg, E.J., Storaas, T., 2012b. Reproductive success and failure - the role of winter body mass in reproductive allocation in Norwegian moose. Oecologia 172, 995-1005. http://dx.doi.org/10.1007/ s00442-012-2547-X.

Milner, J.M., van Beest, F.M., Storaas, T., 2013. Boom and bust of a moose population: a call for integrated forest management. Eur. J. For. Res. 132, 959-967. http:/ dx.doi.org/10.1007/s10342-013-0727-9.

Moen, A., Lillethun, A., Odland, A., 1999. Vegetation. Norwegian Mapping Authority, Hønefoss.

Morellet, N., Gaillard, J.M., Hewison, A.J.M., Ballon, P., Boscardin, Y., Duncan, P., Klein, F., Maillard, D., 2007. Indicators of ecological change: new tools for managing populations of large herbivores. J. Appl. Ecol. 44, 634-643. http:/ dx.doi.org/10.1111/j.1365-2664.2007.01307.x.

Mysterud, A., 2010. Still walking on the wild side? Management actions as steps towards ‘semi-domestication' of hunted ungulates. J. Appl. Ecol. 47, 920-925. http://dx.doi.org/10.1111/j.1365-2664.2010.01836.x.

Månsson, J., Andren, H., Pehrson, A., Bergstrom, R., 2007a. Moose browsing and forage availability: a scale-dependent relationship? Can. J. Zool. -Rev. Can. Zool. $85,372-380$.

Månsson, J., Kalen, C., Kjellander, P., Andren, H., Smith, H., 2007b. Quantitative estimates of tree species selectivity by moose (Alces alces) in a forest landscape. Scand. J. Forest Res. 22, 407-414. http://dx.doi.org/10.1080 02827580701515023.

Månsson, J., Bergstrom, R., Pehrson, A., Skoglund, M., Skarpe, C., 2010. Felled Scots pine (Pinus sylvestris) as supplemental forage for moose (Alces alces): browse availability and utilization. Scand. J. Forest Res. 25, 21-31. http://dx.doi.org/ 10.1080/02827581003620354.

Nanji, R.O., 2013. Diet composition and variation in winter of suplementarily fed moose. MSc Thesis. Hedmark University College, Evenstad.

Nemeth, E., Bossew, P., Plutzar, C., 2005. A distance-dependent estimation of foraging ranges of neighbouring bird colonies. Ecol. Model. 182, 67-73. http:// dx.doi.org/10.1016/j.ecolmodel.2004.07.011.

Nilsson, U., Elfving, B., Karlsson, K., 2012. Productivity of Norway spruce compared to Scots pine in the interior of Northern Sweden. Silva. Fenn. 46, 197-209.

NMI, 2008. eKlima. Norwegian Meterological Institute.

Orians, G.H., Pearson, N.E., 1979. On the theory of central place foraging. In: Horn, D.J., Gordon, R.S., Mitchell, R.D. (Eds.), Analysis of Ecological Systems. Ohio State University Press, Columbus, pp. 155-177.
Pastor, J., Naiman, R.J., 1992. Selective foraging and ecosystem processes in boreal forests. Am. Nat. 139, 690-705.

Peek, J.M., Schmidt, K.T., Dorrance, M.J., Smith, B.L., 2002. Supplemental feeding and farming of elk. In: Toweill, D.E., Thomas, J.W. (Eds.), North American Elk: Ecology and Managment. Smithsonian Institution Press, Washington, pp. 617637.

Persson, I.-L., Danell, K., Bergstrom, R., 2000. Disturbance by large herbivores in boreal forests with special reference to moose. Ann. Zool. Fenn. 37, 251-263.

Putman, R., Langbein, J., Green, P., Watson, P., 2011. Identifying threshold densities for wild deer in the UK above which negative impacts may occur. Mammal Rev. 41, 175-196. http://dx.doi.org/10.1111/j.1365-2907.2010.00173.x.

Putman, R.J., Staines, B.W., 2004. Supplementary winter feeding of wild red deer Cervus elaphus in Europe and North America: justifications, feeding practice and effectiveness. Mammal Rev. 34, 285-306.

R Development Core Team, 2012. R: A Language and Environment for Statistical Computing. R Foundation for Statistical Computing, Vienna, Austria.

Raffel, T.R., Smith, N., Cortright, C., Gatz, A.J., 2009. Central place foraging by beavers (Castor canadensis) in a complex lake habitat. Am. Midl. Nat. 162, 62-73. http:// dx.doi.org/10.1674/0003-0031-162.1.62.

Rinella, M.J., Dean, R., Vavra, M., Parks, C.G., 2012. Vegetation responses to supplemental winter feeding of elk i Western Wyoming. West. North Am. Naturalist 72, 78-83.

Romme, W.H., Turner, M.G., Wallace, L.L., Walker, J.S., 1995. Aspen, Elk, and Fire in Northern Yellowstone-National-Park. Ecology 76, 2097-2106.

Rosenberg, D.K., McKelvey, K.S., 1999. Estimation of habitat selection for centralplace foraging animals. J. Wildl. Manage. 63, 1028-1038. http://dx.doi.org/ $10.2307 / 3802818$.

Shipley, L.A., 2007. The influence of bite size on foraging at larger spatial and temporal scales by mammalian herbivores. 116, 1964-1974. http://dx.doi.org/ 10.1111/j.2007.0030-1299.15974.x.

Shrader, A.M., Kerley, G.I.H., Brown, J.S., Kotler, B.P., 2012. Patch Use in Free-Ranging Goats: Does a Large Mammalian Herbivore Forage like Other Central Place Foragers? Ethology 118, 967-974. http://dx.doi.org/10.1111/j.14390310.2012.02090.x.

Skarpe, C., Jansson, I., Seljeli, L., Bergstrom, R., Roskaft, E., 2007. Browsing by goats on three spatial scales in a semi-arid savanna. J. Arid. Environ. 68, 480-491. http://dx.doi.org/10.1016/j.jaridenv.2006.06.009.

Smith, B.L., 2001. Winter feeding of elk in western North America. J. Wildl. Manage. $65,173-190$.

Solbraa, K., 2002. Veiledning i Elgbeitetaksering. Skogbrukets kursinstitutt, Biri.

Storaas, T., Gundersen, H., Henriksen, H., Andreassen, H., 2001. The economic value of moose in Norway - a review. Alces 37, 97-107.

Storaas, T., Nicolaysen, K.B., Gundersen, H., Zimmermann, B., 2005. Prosjekt Elg trafikk i Stor-Elvdal 2000-2004 hvordan unngå elgpåkjørsler på vei og jernbane. In: Oppdragsrapport Høgskolen i Hedmark Elverum, Norway.

Tange, A.C., 2007. Elgskader på furu, i relasjon til fôringsplasser og bestandegenskaper. MSc. Thesis. Norwegian University of Science and Technology, Trondheim.

Thrash, I., 2000. Determinants of the extent of indigenous large herbivore impact on herbaceous vegetation at watering points in the North-Eastern lowveld, South Africa. J. Arid. Environ. 44, 61-72. http://dx.doi.org/10.1006/jare.1999.0452.

Thrash, I., Derry, J.F., 1999. The nature and modelling of piospheres: a review. Koedoe 42, 73-94.

van Beest, F.M., Gundersen, H., Mathisen, K.M., Milner, J.M., Skarpe, C., 2010a. Longterm browsing impact around diversionary feeding stations for moose in Southern Norway. For. Ecol. Manage. 259, 1900-1911.

van Beest, F.M., Loe, L.E., Mysterud, A., Milner, J.M., 2010b. Comparative space use and habitat selection of moose around feeding stations. J. Wildl. Manage 74 219-227. http://dx.doi.org/10.2193/2009-109.

van Beest, F.M., Mysterud, A., Loe, L.E., Milner, J.M., 2010c. Forage quantity, quality and depletion as scale-dependent mechanisms driving habitat selection of a large browsing herbivore. J. Anim. Ecol. 79, 910-922. http://dx.doi.org/10.1111/ j.1365-2656.2010.01701.x.

van Beest, F.M., Rivrud, I.M., Loe, L.E., Milner, J.M., Mysterud, A., 2011. What determines variation in home range size across spatiotemporal scales in a large browsing herbivore? J. Anim. Ecol. 80, 771-785. http://dx.doi.org/10.1111/ j.1365-2656.2011.01829.x.

Wood, S.N., 2006. Generalized Additive Models. Chapman \& Hall/CRC, Boca Raton, Fla.

Zuur, A.F., Ieno, E.N., Walker, N.J., Saveliev, A.A., Smith, G.M., 2009. Mixed Effects Models and Extensions in Ecology with R. Springer, New York. 